\section{Starting Small... Starting from Scratch}

\section{STACY DILLON}

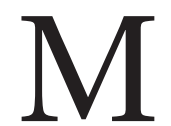

aker Mondays had been brewing in my mind for a while. Being somewhat of a crafter myself, I found myself missing the days of running programs in the public library.

When I looked around, I noticed more and more students hanging out in the library before classes started-they weren't reading or doing homework or even having conversations for the most part. What they were doing was almost entirely smartphone focused.

I figured if I could harness their attention to something concrete and creative, great things could come out of it. So I started from scratch.

Because I am in the school's library in the morning, clearly this was the space where Maker Monday would be held. With a relatively small library, I commandeered one of our tables for the purpose.

I started small, making a sign announcing Maker Monday. This was right before my school's December break, so I decided

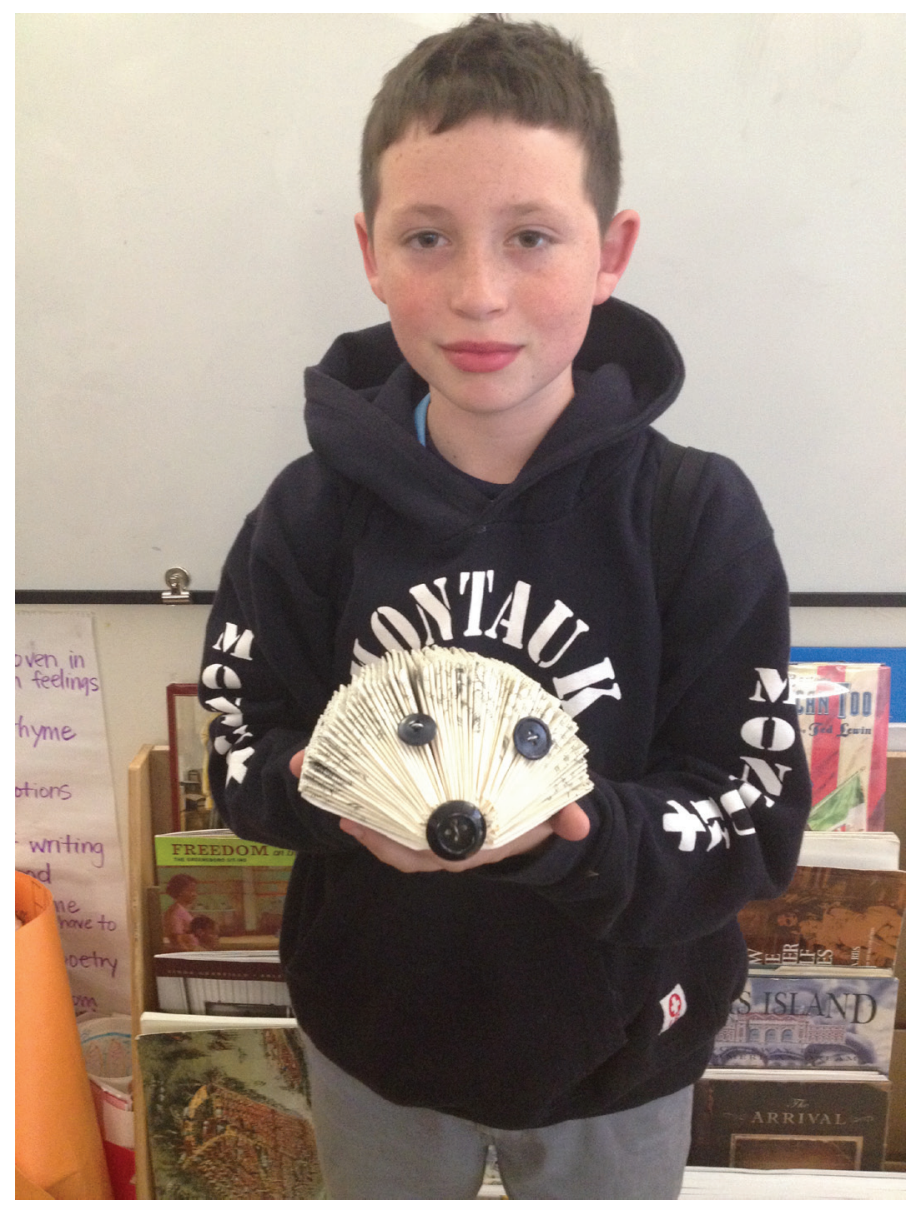

One crafty kid!

to make "wish flakes" with the kids. It's incredibly basic_-just make a paper snowflake and write your wish for the new year on it. The snowflakes could either be hung in the library or the students could take them home.

Our sixth graders came in first, and as the younger students came in, the older ones helped out. It was a modest success, so off to Pinterest I went and I started a Google Doc to plan new projects.

I then let the administration know what I was doing. I am not often one to ask forgiveness instead of permission, but in this

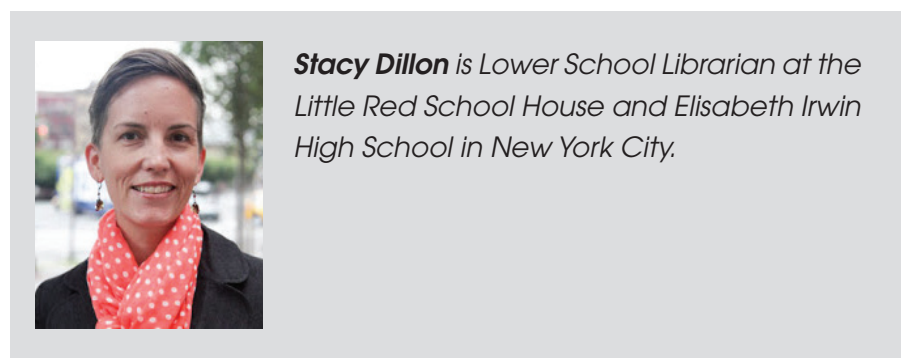




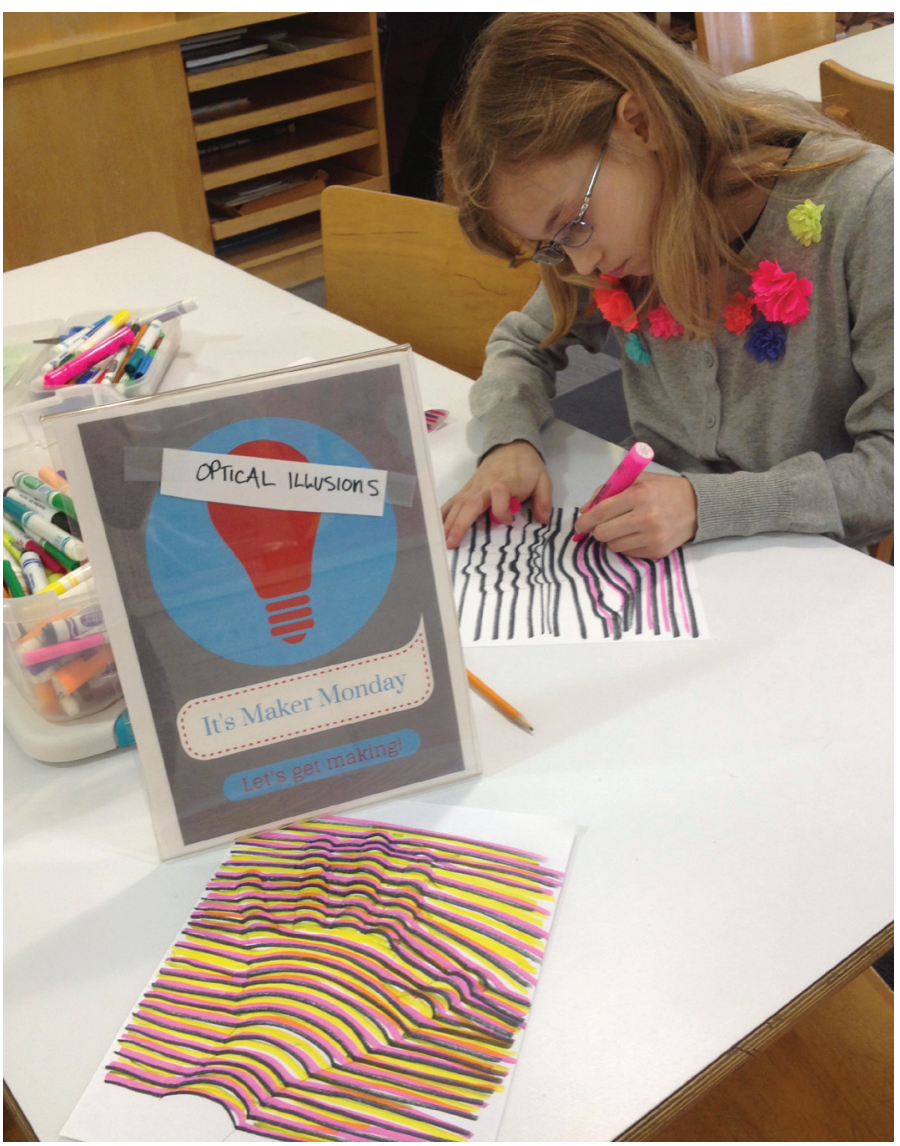

Working on optical illusions.

case I wanted to give it a bit of a test drive first.

My principal wanted to know if I wanted to advertise Maker Mondays, but instead, we have found that word of mouth has been all it has taken to get students involved. There are several students who come running in on Mondays asking, "Stacy, what are we making today?"

I have discovered a few things along the way:

- Students are quite happy with communal projects. A mix of individual and communal projects is what works for us,

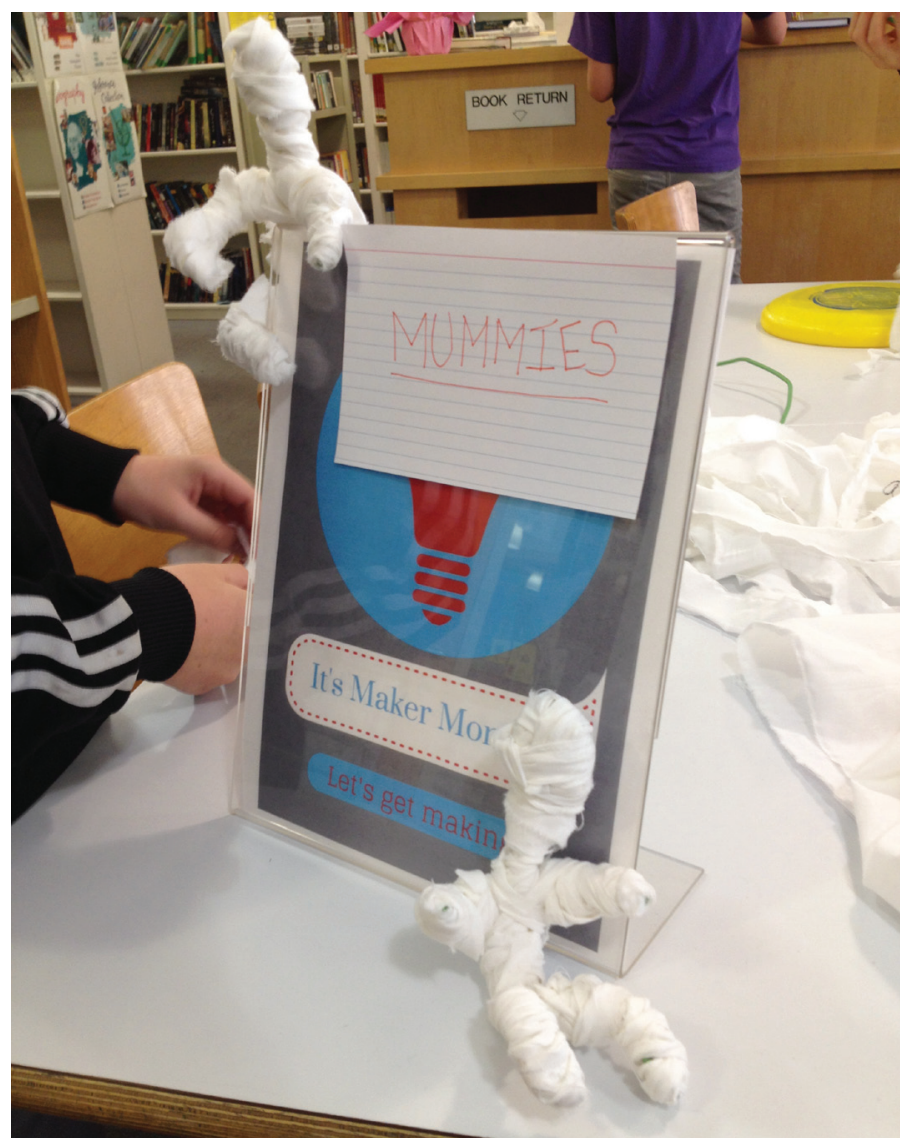

Making mummies.

as does a mix of digital and analog. Students LOVE making things from old books and galley copies. Making hedgehogs from books has been our most successful Maker Monday yet.

- Leveraging the help of older students to help out the younger students has been a lovely thing to observe as well. Our high school is looking at developing a Maker Monday for next year, and a model being considered is the self-directed makerspace in a box model.

My advice? Just get started! You will likely be surprised by the enthusiasm you will see! \&

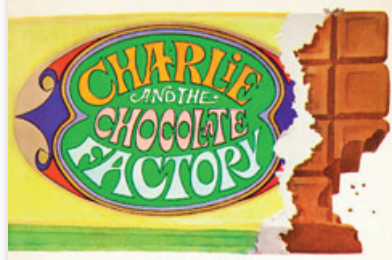

ux Rosild Dahil

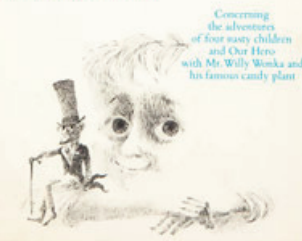

\section{Skype with Roald Dahl Museum}

To celebrate the fiftieth anniversary of Roald Dahl's Charlie and the Chocolate Factory, Penguin is celebrating with a week-long Skype tour of the Roald Dahl Museum and Story Centre.

The tour will include the museum's education manager leading a virtual tour (and engage in a question-and-answer session), and kids will get a look inside Dahl's Writing Hut, featuring his famous chair and the unusual objects he kept on his desk.

Skype opportunities are available the week of Monday, Sept. 29 through Friday, Oct. 3 between 9:30 a.m. and 3 p.m. Eastern. Those interested in scheduling a free virtual visit, email penguinauthorvisits@gmail.com with preferred date and time. For more information, visit https://education.skype.com/projects/9566-penguin-books-roald-dahl -skype-tour-at-the-roald-dahl-museum-and-story-centre. 